\title{
FILMES E EDUCAÇÃO: ALGUMAS TRAVESSIAS ${ }^{1}$
}

\author{
Diogo José Bezerra dos Santos ${ }^{2}$ \\ Giovana Scareli ${ }^{3}$
}

\section{Início da travessia}

O presente trabalho é parte da pesquisa de iniciação científica "Ser-tão Minas: uma Cartografia Cinematográfica do Sertão Mineiro", que buscou compreender uma possível construção do ser-tão mineiro por meio das obras cinematográficas e refletir sobre essas possíveis educações: visual, estética, cultural. A pesquisa foi realizada em três momentos: primeiro, foi feito um levantamento dos filmes lançados nos últimos cinquenta anos e que apresentavam, através de seus cenários, paisagens, habitantes e elementos culturais, o estado de Minas Gerais. Num segundo momento, foram produzidos alguns gráficos por meio do cruzamento de informações referentes a essas produções e, por fim, foi escolhido um filme para ser analisado. O filme escolhido foi Acidente, de Cao Guimarães e Pablo Lobato, de 2006, por considerarmos um filme que apresenta o estado mineiro de uma maneira diferente da maioria dos filmes encontrados.

O conjunto de imagens produzido pelo cinema chega às mais diferentes pessoas que assistem aos filmes. Essas produções auxiliam na construção da imagem de Brasil, de brasileiro, de sua cultura, de seus costumes e que, aliado à literatura, às fotografias, às histórias em quadrinhos, promovem identificações, afecções, um saber sobre esses lugares e seus povos. Este saber, se constrói mediado pelas imagens que foram feitas para serem consumidas por meio desses produtos culturais. Sendo assim, podemos afirmar que, de alguma forma, somos educadas por elas.

Partindo dessas considerações inicias, a travessia desse artigo está em problematizar o uso de filmes na educação, ponderando sobre a Lei 13.006, que ficou conhecida como a Lei do cinema nacional na escola; a apreciação de um trecho do filme Acidente e a aposta no cinema como possibilidade de resistência aos estereótipos e clichês em favor de uma educação emancipadora.

\section{Primeiras aproximações}

Percebemos na pesquisa de iniciação científica que grande parte dos filmes que apresentam o estado de Minas Gerais o fazem através de imagens e narrativas padronizadas, as quais recorrentemente, apresentam imagens cinematográficas em plano aberto, na qual vemos um vasto horizonte cercado por rios, campos, veredas e buritis. Também é comum vermos fazendas, vilarejos de terra batida, igrejas, sobrados, crucifixos, fogões à lenha e carros de boi. Em relação aos personagens, em geral se apresentam ingênuos, religiosos, com um forte sotaque, que são, em geral, fazendeiros, vaqueiros, jagunços, padres ou trabalhadores de lavoura. Essas obras reforçam elementos que já fazem parte do nosso senso comum, que junto a outros inúmeros ícones culturais ajudam a construir e difundir um tipo de visão padronizada do estado de Minas Gerais e de seus habitantes.

\footnotetext{
${ }^{1}$ Esse artigo é um dos desdobramentos da pesquisa de iniciação científica Ser-tão Minas: uma cartografia cinematográfica do sertão mineiro, orientado pela Profa. Dr. Giovana Scareli, encerrado em 2016 e que foi apresentado no $7^{\circ}$ Encontro com Imagens e Filosofia, realizado pelo Grupo de Pesquisa em Educação, Filosofia e Imagem (GEFI), na Universidade Federal de São João del-Rei (UFSJ), em setembro de 2017.

${ }^{2}$ Licenciatura e Bacharelado em História - UFSJ. Mestrando em Educação - UFSJ. E-mail: diogo.oroiz@gmail.com.

${ }^{3}$ Professora do Departamento de Ciências da Educação - DECED/UFSJ e coordenadora do GEFI.
} 
A promulgação da Lei $n^{\circ} 13.006$ de 2014, que tornou obrigatória a exibição de filmes de produção nacional nas escolas de ensino básico por, no mínimo, duas horas mensais, tornou oportuno este trabalho para que pensemos quais as potencialidades e desafios que o cinema pode proporcionar para a área da Educação. Para obtermos um parâmetro de como o cinema é comumente utilizado em sala de aula, realizamos uma busca ao banco de teses da Coordenação de Aperfeiçoamento de Pessoal de Nível Superior (CAPES) e procuramos pelas palavras chaves "cinema" e "educação", o que nos permitiu uma constatação um tanto quanto instigante para uma reflexão: grande parte dos trabalhos que relacionam cinema e educação apresentam o cinema em sala de aula como um recurso positivo e facilitador do ensino-aprendizagem. A escassez de críticas ao cinema como um recurso manipulador e normatizador de condutas, associada a obrigação da exibição de filmes em sala de aula nos moveu a refletir sobre o assunto. Cabe lembrar, para reforçar a importância deste debate, que o cinema foi muito utilizado como instrumento de propaganda e manipulação pelo Estado e pela indústria, através da construção e difusão de identidades, de modos de pensar e agir, fazendo com que o cinema fosse mais utilizado na perspectiva da doutrinação do que no estímulo ao pensamento.

Mas o que pode o cinema na Educação para além deste uso que vincula a imagem visual à normatização de condutas e modos de pensar e agir? Quem seriam os beneficiários desta lei 13.006? O que pode o cinema, quando utilizado como um vetor de resistência aos clichês e estereótipos em favor de uma educação emancipadora?

No cinema brasileiro, há um grande número de produções que são utilizadas em sala de aula, entretanto, apesar de consumirmos esses bens culturais nem sempre investigamos que tipo de saberes é possível constituir a partir dessa linguagem que expressa, encena, documenta, caracteriza, apresenta elementos do real, sempre numa construção sistematizada, pensada, selecionada e editada para estar na tela. Segundo Milton José de Almeida (1995, p. 14),

[...] a cultura produz e também reproduz, faz nascer, renascer o conhecimento, as sabedorias, mostra novamente o antigo, demonstra o novo, o saber-fazer dos homens. É sempre contemporânea do presente, até mesmo quando expõe o velho, a cultura que já foi. Ela se expõe, ao mesmo tempo, para a produção e consumo, independente de faixa etária, formação e pré-requisitos.

Neste movimento de produção e reprodução realizado pela cultura, somos ensinados por ela, adquirimos saberes, experimentamos o antigo e o novo por meio de imagens e narrativas, que algumas vezes nos proporcionam a crítica sobre esta cultura e muitas vezes, perpetuam clichês e estereótipos.

Num artigo intitulado "Filmes e escola: isto combina?" (1999), Cristina Bruzzo diz que o que torna favorável os filmes estarem presentes em situações educacionais é que "A realização cinematográfica é uma forma de expressão interessante, na medida em que seus autores tenham algo a propor como reflexão sobre a vida, como uma forma de falar do mundo e questionar nossas ações e instigar nossos sonhos.” (p. 3). Concordamos com Bruzzo (1999) e relacionamos ainda, uma questão formulada por Deleuze (1999) "o que é isso senão aquilo que somente o cinema pode fazer?

O que há de especial no cinema que só ele pode fazer? De que forma ele fala do mundo? Como apresenta esse mundo? Como cria mundos, modos de vida, sonhos? O que nos instiga? Essas questões são instigantes para pensar os filmes na educação pois, como afirma, Cézar Migliorin (2015, p. 33) "Precisamos levar em consideração que o cinema já faz parte da educação." Assim, precisamos refletir sobre o que os filmes podem mobilizar de pensamentos, sonhos, modos de ver o mundo. 
Atrelando essas considerações ao objetivo desse trabalho, será que os filmes utilizados em sala de aula estão conservando clichês, modos estereotipados de conhecer o mundo ou estão rompendo com essa prática e estimulando o pensamento?

Acreditamos que os espaços educacionais sejam lugares para estimular o pensamento e produzir diferenças, multiplicando singularidades. Defendemos, assim como o professor Silvio Gallo (2015), que:

[...] a escola não é local de formação orientada para seja o que for: preparação de cidadãos para o mundo político, de trabalhadores para o mundo do trabalho, de consumidores para fazer girar o capital; nem mesmo de preparação para a vida. (...) ao contrário, a escola seria lugar de desorientação, de des-caminho, de de-formação na medida em que desorientação, descaminho, deformação são princípios para uma experimentação de si mesmo que permita orientar-se, escolher caminhos, formar-se. Educação como formação de si. (Gallo, 2015, p. 201-202)

Em nosso mundo "hipervisual", é importante que a escola, em favor de uma educação realmente emancipadora, busque criar uma resistência aos clichês, às imagens e narrativas carregadas de verdades preestabelecidas, pois, na maioria das vezes, as imagens chegam dessa forma, como verdades a serem recebidas e assimiladas, sem resistência.

A presença de filmes na escola deve buscar a contramão dos clichês, das verdades, da reprodução, da manutenção dos estereótipos. Dessa forma, cabe pensar que tipo de filme será escolhido para esse encontro. Bruzzo (1999, p. 3) afirma que:

Nem todos os filmes se equivalem na concepção do que seja realização cinematográfica, nem todos os diretores procuram se expressar da mesma forma e nem todos os espectadores buscam as mesmas sensações ao entrar no cinema ou ligar a televisão.

Quando pensamos na Lei 13.006 que obriga a exibição de filmes nacionais na escola, nos defrontamos com duas questões importantes a partir dessa afirmação de Bruzzo, se nem todos os filmes se equivalem, como escolher as produções que irão para a escola? Quem fará essa escolha? Será que os estudantes terão alguma participação nessa escolha?

O cinema pensado, produzido, considerado como uma obra de arte é um ato de resistência, como indica Deleuze nas várias citações de filmes e músicas em "O ato de criação" (1999). Ao relacionar o cinema a obra de arte, pensamos que a escolha de filmes deva ser muito rigorosa, no sentido de que, quem vai escolher, deve conhecer, minimamente, a linguagem cinematográfica; que o filme escolhido possa provocar diferentes sensações, que estimule o pensamento, mas também sentimentos, sensações, afecções.

Se, por um lado, os clichês perpetuam imagens e ideias, por outro, as imagens também podem escapar aos clichês, quando produzidas dentro de um trabalho artístico da linguagem cinematográfica, das ideias de cinema trabalhadas a partir da criação, da invenção criativa com os elementos dessa linguagem. Escolhemos para pensar um pouco mais sobre essas ideias, um trecho do filme Acidente, cartografado durante a pesquisa de iniciação científica A escolha desse filme se deu por sua potência cinematográfica e como um contraponto aos filmes que expressam o estado de Minas Gerais e seus habitantes a partir de clichês, o que ao nosso ver, desestimula o pensamento e ajuda a perpetuar estereótipos. 


\section{Acidente: travessias no filme}

O filme parte de um poema composto por nomes de vinte cidades do interior de Minas Gerais pelas quais os diretores viajaram.

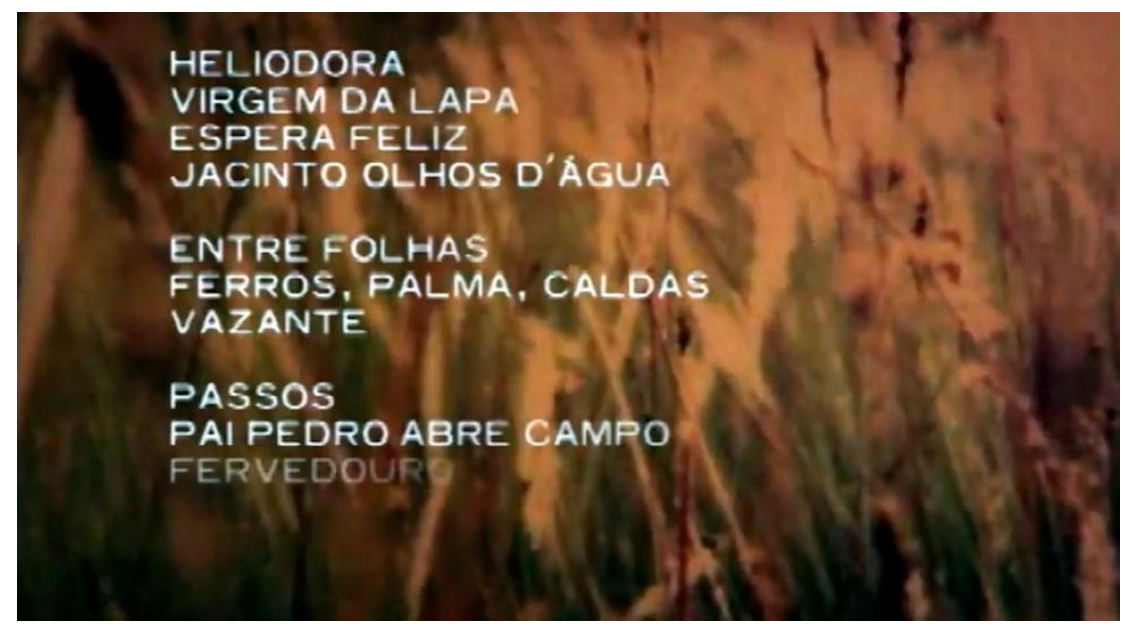

Fig. 1: fotograma. Fonte: retirada da internet ${ }^{4}$
Heliodora

Virgem da Lapa

Espera Feliz

Jacinto Olhos D’Água

Entre Folhas

Ferros, Palmas, Caldas

Vazante

Passos

Pai Pedro Abre Campo

Fervedouro Descoberto

Tiros, Tombos, Planura

Águas Vermelhas

Dores de Campos

Segundo a sinopse do documentário, encontrada no site do cineasta Cao Guimarães, a partir deste poema,

[...] o corpo rítmico do filme se abre ao imprevisto e ao improviso. Instigados pelos nomes destas cidades, a equipe de filmagem percorre por uma primeira vez cada uma delas. Num movimento de imersão, o filme se faz através de duas camadas narrativas, uma formada pela história do poema e outra pelos eventos ordinários que surgem acidentalmente diante da câmera em cada uma das cidades. ${ }^{5}$

A sequência do filme, selecionada para apreciação, foi feita segundo alguns critérios propostos pelo "método documentário" de Ralf Bohnsack (2010). Tentamos dividir a análise seguindo seis passos propostos pelo autor, que são: discriminação da fonte; análise préiconográfica; análise iconográfica; composição formal; interpretação icônico-iconológica e, por fim, os elementos textuais. A sequência do filme que decupamos vai dos onze minutos até os quinze minutos do filme e se passa na cidade de Espera Feliz, conforme aparece na figura 1, com nome e o mapa ao lado. Eduardo Valente ${ }^{6}$ afirma que a chave de Acidente é "não se dar a ver completamente". O filme "desafia o olhar e a audição do espectador". Realmente, o filme usa, exaustivamente, o primeiríssimo e o primeiro plano. Não trataremos da audição nesse texto, mas pode ser um dos elementos de uma próxima travessia com esse filme.

A primeira cena se inicia com a câmera parada, focalizando em primeiro plano uma moldura com uma fotografia pendurada em uma parede, pelo barulho de jogo de sinuca, a música e as conversas, podemos deduzir que a cena se passa dentro de um bar e, pelo sotaque das pessoas que conversam também deduzimos que se trata de um bar do interior de Minas

\footnotetext{
${ }^{4}$ Disponível em: 〈https://projetofreeway.wordpress.com/tag/cao-guimaraes-pablo-lobatto-acidente-processo-criativo/> Acesso em: 30 out. 2017.

${ }^{5}$ Disponível em: 〈http://www.caoguimaraes.com/obra/acidente/>. Acesso em: 25 out. 2017.

${ }^{6}$ VALENTE, Eduardo. Percurso de Acidente. Disponível em: 〈http://www.revistacinetica.com.br/acidentepercurso.htm〉. Acesso em: 26 out. 2017.
} 
Gerais. De repente, entra na cena uma pessoa de costas, arruma a moldura e sai. Há um corte. Em primeiríssimo plano aparece uma roda de bicicleta. A câmera parada, focaliza essa roda até que uma mão entra em cena e fecha o pino da câmara de ar do pneu. Corte na cena. A câmera parada, em primeiro plano aparecem dois copos jogados ao chão, ao fundo, os sons são de crianças correndo e brincando e, com isso, deduzimos que a cena se passa dentro de um colégio. De repente, os copos que estavam sendo focalizados se arrastam com o vento. Corte na cena.

Em primeiríssimo plano, a câmera focaliza um canudo de plástico, a cena segue até que um rosto também em primeiríssimo plano aparece utilizando o canudo para beber alguma coisa. Corte na cena. A câmera focaliza em primeiríssimo plano, pesos de ferro enumerados de um a quatorze. Pelos sons da cena podemos deduzir que se passa dentro de uma academia. A cena segue até que a metade dos pesos seja levantada. Após isso, há um corte. A câmera parada, focaliza em plano médio, cinco mesas grandes com bancos de madeira em cima, após o barulho de um sinal sonoro, entra uma pessoa e começa a retirar os bancos de cima das mesas e colocá-los no chão. Temos a impressão que a cena se passa dentro de um refeitório de um colégio. Corte.

A Câmera, parada, focaliza em primeiro plano, um poste com a luz apagada, após uma batida do sino a luz se acende. Corte. A câmera, parada, focaliza em primeiríssimo plano, um copo vazio, a cena segue até que uma mão segurando uma garrafa térmica entra no enquadramento e despeja café dentro do copo. Vemos nesta cena a maior quantidade de ícones que fazem referências ao estado de Minas Gerais, o café, o doce de banana, o doce de amendoim, o sotaque das pessoas que conversam ao fundo. Corte. A câmera, focaliza em primeiro plano, um cachorro deitado no chão e um pedaço de pastel jogado na sua frente. A cena segue até o cachorro comer o pastel. Pelos sons e conversas, deduzimos que se passa dentro de um bar. Corte.

A câmera parada, focaliza um muro com um refletor de luz no canto superior esquerdo e um cano de água no lado direito, de repente começa a sair água do cano. Corte. A sequência encerra com a câmera focalizando uma janela com uma cortina enrolada, a cena segue até que uma pessoa entra e desenrola a cortina. Corte para outra sequência.

Segundo Úrsula Rösele,

Acidente passeia no ritmo de sua poesia e na capacidade acidental da câmera de captar as minúcias existentes no microcosmo de cada um daqueles lugares. Existe uma busca pela beleza percebida pela câmera discreta que passeia quase que solitária, procurando no imprevisto a razão de seu caminhar. O tom amarelado, as paredes descobertas de tinta, o silêncio, a rima do nome com aquilo que evoca. ${ }^{7}$

Percebemos que, apesar da ausência de clichês, os diretores se utilizam de signos e ícones que estão muito presentes na cultura do estado de Minas Gerais, no entanto, nada é visto explicitamente, falta algo que o espectador precisa completar, algo que está entre o espectador e a obra. Está é, justamente, a potência de Acidente: estimular a imaginação e o pensamento, nos facilitando a fuga dos clichês.

Para Luis Buñuel (1983, p. 335),

Aos filmes falta, em geral, o mistério, elemento essencial a toda obra de arte. Autores, diretores e produtores evitam cuidadosamente perturbar nossa tranquilidade abrindo a janela maravilhosa da tela ao mundo libertador da poesia; preferem fazê-la refletir temas que poderiam ser o prolongamento de

\footnotetext{
7 Texto sobre o filme de Ursula Rösele. Disponível em: <http://www.caoguimaraes.com/wordpress/wpcontent/uploads/2013/06/Acidente.pdf>. Acesso em: 26 out. 2017.
} 
nossas vidas comuns, repetir mil vezes o mesmo drama, fazer-nos esquecer as horas penosas do trabalho cotidiano.

Talvez, Buñuel pudesse gostar de assistir Acidente, pois nos parece que o filme contém essa poesia, esse mistério, tão caro ao diretor e também a nós, quando pensamos o uso de filmes em sala de aula.

\section{Algumas reflexões na/da travessia}

Na obra "Eichmann em Jerusalém: um relato sobre a banalidade do mal", de Hannah Arendt, encontramos uma justificativa para apoiarmos a utilização do cinema como um vetor de resistência às representações estereotipadas e aos clichês. Na obra, a autora analisa o julgamento de Adolf Eichmann, o responsável pelo envio dos judeus para os campos de concentração na Alemanha Nazista. A análise da autora demonstra que a impossibilidade de pensar diferente do discurso dominante é que torna um indivíduo obediente aos mandos do Reich, isto é, as atitudes de Eichmann eram produtos de sua incapacidade de pensar.

Vagamente consciente de uma incapacidade que deve tê-lo perseguido ainda na escola - chegava a ser um caso brando de afasia - ele [Eichmann] pediu desculpas dizendo: "Minha única língua é o oficialês [Amtssprache]". Mas a questão é que o oficialês se transformou em sua única língua porque ele sempre foi genuinamente incapaz de pronunciar uma única frase que não fosse um clichê. [...] Sem dúvida, os juízes tinham razão quando disseram ao acusado que tudo o que dissera era "conversa vazia" - só que eles pensaram que o vazio era fingido, e que o acusado queria encobrir outros pensamentos que, embora hediondos, não seriam vazios. Essa ideia parece ter sido refutada pela incrível coerência com que Eichmann, apesar de sua má memória, repetia palavra por palavra as mesmas frases feitas e clichês semi-inventados (quando conseguia fazer uma frase própria, ele a repetia até transformá-la em clichê) toda vez que se referia a um incidente ou acontecimento que achava importante. Quer estivesse escrevendo suas memórias na Argentina ou em Jerusalém, quer falando com o interrogador policial ou com a corte, o que ele dizia era sempre a mesma coisa, expressa com as mesmas palavras. Quanto mais se ouvia Eichmann, mais óbvio ficava sua incapacidade de pensar, ou seja, de pensar do ponto de vista de outra pessoa. Não era possível nenhuma comunicação com ele, não porque mentia, mas porque se cercava do mais confiável de todos os guarda-costas contra as palavras e a presença dos outros, e portanto contra a realidade enquanto tal (ARENDT, 2011, p. 61-62)

Neste sentido, o mal era criado pela narrativa que repetia e transformava tudo em clichês. Ao trazer esse pensamento de Arendt (2011) para esse texto, estamos aproximando essa ideia de que os clichês, difundidos pelas obras cinematográficas, que apresentam as mesmas imagens de um lugar, de um povo, de uma cultura, difundem e reproduzem estereótipos e clichês. $\mathrm{O}$ uso desse tipo de filme na Educação não provoca o pensamento, apenas reproduz o senso comum e com isso podem educar no sentido da repetição, da doutrinação, na incapacidade de pensar, de criar, de inventar.

$\mathrm{O}$ cinema como estímulo ao pensamento, torna-se um vetor resistência às representações dominantes, aos estereótipos e clichês, abrindo espaço para a experimentação, fazendo devir o pensamento. O combate a utilização de clichês nos ambientes educacionais, com vistas a uma 
educação emancipadora deve ser a de desconstruir os preconceitos estabelecidos e liberar o pensamento para suas potências criativas.

Essa emancipação é pensada a partir de Jaques Rancière, em O Mestre Ignorante (2010), que traz as lições extraídas a partir do trabalho do pedagogo e filósofo Joseph Jacotot, que mais do que um novo método de ensino, tratou de estabelecer uma pedagogia que tivesse a liberdade como princípio e a emancipação como método. Esse método propõe que qualquer pessoa pode ensinar qualquer coisa, mesmo que seja ignorante naquele assunto, por meio do exercício da inteligência. O mestre ignorante que se propõe a trabalhar no sentido da emancipação, enquanto ensina algo que ignora, estimula seu aluno a pensar por si próprio, sem a explicação do mestre que, ao contrário, não estimula o pensamento do aluno.

Apoiados, portanto, nos conceitos de clichê (Arendt) e emancipação (Rancière), consideramos que uma das principais preocupações dos professores, que tiverem a tarefa de cumprir a lei que obriga a exibição de filmes nacionais nas escolas, ou ainda de quem pretende lançar mão de filmes na educação, consista em procurar obras que não sejam meras reproduções de clichês, de signos que reproduzem o senso comum, de histórias "batidas" com início, meio e fim previsíveis e que, portanto, não exigem nenhum pensamento mais elaborado, não expandem a imaginação e não promovem a emancipação dos espectadores.

Ao apresentar um mundo que escapa aos estereótipos e clichês, o cinema pode abrir espaços nas representações que nos impedem de pensar, fazendo devir o pensamento. Esta função, vai em convergência ao que Ismail Xavier (2008, p. 15) sugere como função principal do cinema para a educação:

Para mim, o cinema que "educa" é o cinema que faz pensar [...]. A questão não é "passar conteúdos", mas provocar a reflexão, questionar o que, sendo um constructo que tem história, é tomado como natureza, dado inquestionável.

Consideramos que a potência da educação está em promover o pensamento autônomo, considerando as individualidades e especificidades de cada pessoa. Neste sentido, o cinema pode servir como um "ato de resistência" (Deleuze, 1999), no sentido de ser utilizado como um agente do pensamento, como "instrumento de poesia" (Buñuel, 1983), estimulando a imaginação, a "emancipação" (Rancière, 2010) e, quem sabe, a invenção de novas travessias.

\section{Referências}

ACIDENTE. Diretores Cao Guimarães e Pablo Lobato. Documentário. Belo Horizonte/MG/Brasil, 2006, 72min colorido.

ALMEIDA, Milton José de. Imagens e sons: a nova cultura oral. São Paulo: Cortez, 1994.

ARENDT, Hannah. Eichmann em Jerusalém: um relato sobre a banalidade do mal. São Paulo: Companhia das Letras, 2011.

BOHNSACK, Ralf. A interpretação de imagens segundo o método documentário. In: WELLER, Wivian; PFAFF, Nicole (Org.). Metodologias da pesquisa qualitativa em educação: teoria e prática. Petrópolis, RJ: Vozes, 2010.

BRUZZO, C. Filmes e escola: isto combina? Ciência \& Ensino, n. 6, 1999. Disponível em: <http://prc.ifsp.edu.br/ojs/index.php/cienciaeensino/article/view/50/49>. Acesso em: 25 out. 2017. 
DELEUZE, Gilles. O Ato de Criação. Tradução: José Marcos Macedo. In. Folha de São Paulo, 27/06/1999. Transcrição de conferência realizada em 1987.

GALLO, Sílvio. A escola: lugar de formação?. In: SCARELI, Giovana (Org.). Educação, culturas, políticas e práticas educacionais e suas relações com a pesquisa. Porto Alegre, RS: Sulina, 2015.

MIGLIORIN, Cézar. Inevitavelmente cinema: educação, política e mafuá. Rio de Janeiro: Beco do Azougue, 2015.

RANCIÈRE, Jacques. $O$ mestre ignorante: cinco lições sobre emancipação intelectual. Tradução Lílian do Valle. 3. ed. Belo Horizonte: Autêntica, 2010.

RÖSELE, Ursula. Acidente, de Cao Guimarães e Pablo Lobato. Disponível em: $<$ http://www.caoguimaraes.com/wordpress/wp-content/uploads/2013/06/Acidente.pdf $>$. Acesso em: 26 out. 2017.

VALENTE, Eduardo. Percurso de Acidente. Disponível em <http://www.revistacinetica.com.br/acidentepercurso.htm>. Acesso em 30 abr. 2017.

XAVIER, Ismail (Org.). A experiência do cinema: antologia. 4 ed. Rio de Janeiro: Graal Embrafilmes, 1983.

XAVIER, Ismail. Um cinema que "educa" é um cinema que (nos) faz pensar: entrevista com Ismail Xavier. Educação \& Realidade (Dossiê cinema e educação), Porto Alegre, v. 33, n. 1, p. 13-20, jan./jun. 2008. 